\title{
Patient outcomes influenced by reduced lymphocyte counts after dimethyl fumarate initiation
}

\section{OPEN}

Katy Wright, PA-C

Mandy D. Winkler, RN, BSN

Braeden D. Newton, BSc Maria Pia Sormani, PhD

Darin T. Okuda, MD

Correspondence to

Dr. Okuda:

darin.okuda@UTsouthwestern. edu

\section{ABSTRACT}

Objective: To examine the temporal profile of absolute and lymphocyte subset data from dimethyl fumarate (DMF) start and relationships to disease behavior.

Methods: A retrospective study performed on patients with an existing diagnosis of MS and a history of DMF exposure from a single MS center. Demographic, laboratory, and corresponding clinical relapse and MRI data were recorded from baseline and in 3-4-month intervals after treatment initiation extending to 3 years. The Spearman rank coefficient and mixed-effects models were used to assess longitudinal correlations between cell counts and measures of disease activity.

Results: A total of 292 patients with MS (228 women; median age at DMF initiation: 40.6 years, range: 16.1-66.7 years) were identified. An increased risk of disease activity was associated with higher absolute lymphocyte count (ALC) values at 3 months ( $p=0.001$, OR: 1.82 ) and at 6 months ( $p=0.032$, hazard ratio: 1.73). A reduced risk of disease evolution in patients with lower ALC values $<1,200$ cells/ $\mu \mathrm{L}$ compared with midtier $(1,210-1,800 \mathrm{cells} / \mu \mathrm{L})$ and the highest tertile $(>1,810$ cells $/ \mu L)$ was observed $(p=0.01)$.

Conclusions: Reductions in ALC values at months 3 and 6 after treatment initiation appear to be associated with improved clinical and radiologic outcomes. These data alone may help to provide a better understanding of both the safety and efficacy of DMF. Neurol Neuroimmunol Neuroinflamm 2017;4:e397; doi: 10.1212/NXI.0000000000000397

\section{GLOSSARY}

$\mathbf{A L C}=$ absolute lymphocyte count; $\mathbf{D M F}=$ dimethyl fumarate; $\mathbf{H R}=$ hazard ratio; $\mathbf{N K}=$ natural killer; $\mathbf{W B C}=$ white blood cell.

Dimethyl fumarate (DMF), marketed commercially as Tecfidera, is a twice-daily, oral diseasemodifying therapy approved for the treatment of relapsing-remitting MS. While the exact mechanism of action is not entirely understood, DMF is known to cause reductions in white blood cell (WBC) count and absolute lymphocyte count (ALC) values. Mean ALC reductions of approximately $30 \%$ were previously observed within the first year of treatment. ${ }^{1}$ Significant ALC reductions were also described, resulting in grade III lymphopenia (ALC $<500$ cells/ $\mu \mathrm{L}$ ) in approximately $5 \%$ of patients. ${ }^{1}$ Recent studies have also reported reductions in $\mathrm{T}$ cells and B cells. ${ }^{2,3}$

Several cases of progressive multifocal leukoencephalopathy (PML) have occurred in DMFtreated patients with sustained lymphopenia ( $>6$ months). While most cases have occurred in patients with ALC $<500$ cells/ $\mu \mathrm{L}$, fumarate-related PML has developed with ALC values as high as 792 cells/ $\mu \mathrm{L}$, highlighting the need for careful surveillance. ${ }^{4-6}$

Like many immunomodulatory treatments, DMF influences several targets, having antiinflammatory and immunomodulatory properties along with neuroprotective effects. ${ }^{78}$ However, this does not completely explain reductions in ALCs and lymphocyte subsets. ${ }^{2,3}$

From the UT Southwestern Medical Center (K.W., M.D.W., B.D.N., D.T.O.), Department of Neurology and Neurotherapeutics, Multiple Sclerosis and Neuroimmunology Imaging Program, Clinical Center for Multiple Sclerosis, Dallas, TX; and Department of Health Sciences (DISSAL) (M.P.S.), University of Genoa, Italy.

Funding information and disclosures are provided at the end of the article. Go to Neurology.org/nn for full disclosure forms. The Article Processing Charge was funded by the authors.

This is an open access article distributed under the terms of the Creative Commons Attribution-NonCommercial-NoDerivatives License 4.0 (CC BY-NC-ND), which permits downloading and sharing the work provided it is properly cited. The work cannot be changed in any way or used commercially without permission from the journal. 


\begin{tabular}{|lllllllll|}
\hline Table 1 & \multicolumn{3}{l}{$\begin{array}{l}\text { Summary of data available at each time } \\
\text { point for leukocyte counts, absolute } \\
\text { lymphocyte counts (ALCs), and each }\end{array}$} \\
subpopulation \\
Time, min & WBC & ALC & CD3 & CD4 & CD8 & CD19 & NK \\
\hline 0 & 266 & 263 & 50 & 50 & 50 & 22 & 22 \\
\hline 3 & 152 & 148 & 45 & 46 & 46 & 22 & 21 \\
6 & 122 & 119 & 40 & 40 & 41 & 19 & 19 \\
\hline 9 & 81 & 80 & 35 & 34 & 34 & 11 & 9 \\
12 & 143 & 144 & 61 & 61 & 61 & 28 & 26 \\
18 & 130 & 129 & 65 & 65 & 65 & 34 & 31 \\
\hline 24 & 108 & 107 & 77 & 77 & 77 & 37 & 35 \\
30 & 75 & 75 & 67 & 67 & 67 & 47 & 44 \\
36 & 34 & 34 & 29 & 29 & 29 & 26 & 25 \\
\hline
\end{tabular}

Abbreviations: $\mathrm{NK}=$ natural killer; $\mathrm{WBC}=$ white blood cell.

As $\mathrm{T}$ cells and $\mathrm{B}$ cells contribute to MS pathogenesis, it is conceivable that some degree of therapeutic effect could be related to decreases in these cell counts. This investigation aimed to evaluate the temporal profile of absolute and lymphocyte subset changes following exposure to DMF and the relationship between these features and clinical and radiologic measures of disease.

METHODS Clinical subjects. A retrospective chart review was conducted on patients with relapsing-remitting MS and a history of DMF exposure at the Clinical Center for Multiple Sclerosis at UT Southwestern Medical Center in Dallas, Texas. This study was approved by the UT Southwestern Medical Center Institutional Review Board.

Demographic and laboratory data, including WBC, ALC, CD3, CD4, CD8, natural killer (NK), and CD19 cell counts, and corresponding clinical relapse and MRI data were recorded as part of routine management. Data were obtained at baseline and serially in 3-4-month intervals after treatment extending to 3 years (table 1). MRI data were acquired prior to DMF initiation, 6 months after treatment, and annually thereafter. Disease progression was defined by the presence of new or old neurologic symptom attributable to CNS demyelination, persisting for $>24$ hours in the absence of fever or infection, or new $\left(>3 \mathrm{~mm}^{2}\right)$ or enlarging lesions observed on repeat imaging of the brain or spinal cord. Clinical relapses and new radiologic activity were verified by the treating provider. Clinical relapse data were not included if they occurred within the first 3 months of treatment. Radiologic advancement was scored only if new imaging features supportive of in situ demyelination were observed between the 6-month post-DMF MRI and subsequent imaging studies.

Statistical analysis. Correlations between ALCs and clinical outcomes were evaluated by the Spearman rank coefficient. Mixed linear models were used to assess the time course of ALC changes over multiple time points and the longitudinal correlation of ALCs to patient outcome data. The association between the ALC and time to a first clinical relapse or radiologic advancement was assessed by a Cox model, and Kaplan-Meier curves were generated to display the results. $p$ Value of $<0.05$ was considered statistically significant. Not all patients completed scheduled serologic assessments or remained on therapy for $\geq 3$ months. If ALC values were missing at month 6 , ALC values from month 3 were imputed for those who remained on therapy to increase the available data in the survival analysis.

RESULTS Data were collected on 295 patients with relapsing-remitting MS exposed to DMF. Three patients were excluded because of insufficient laboratory and imaging assessments. A total of 292 patients served as the study cohort (228 women [78\%], median age at DMF start date: 40.6 years, range: 16.1-66.7). The median disease duration at DMF initiation was 4.5 years $(0.0-$ 34.9) (table 2).

A correlation between WBC and ALC $(r=0.46$, $p<0.001), \mathrm{CD} 3(r=0.66, p<0.001), \mathrm{CD} 4(r=$ $0.60, p<0.001), \mathrm{CD} 8(r=0.49, p<0.001)$, and $\mathrm{CD} 19(r=0.55, p=0.009)$ was found at baseline. At 6 months, a correlation between WBC and ALC ( $r=$ $0.56, p<0.001), \mathrm{CD} 3(r=0.49, p=0.001), \mathrm{CD} 4$

\section{Table 2 Demographic and clinical characteristic data of the study cohort}

Diagnosis: relapsing-remitting MS $(n=292)$

Age at first symptom, median years 32.1 (9.8-63.9) (range)

Age at Tecfidera start

$40.6(16.1-66.7)$

Sex

F

$228(78 \%)$

M

$64(22 \%)$

Ethnicity

Non-Hispanic

270 (93\%)

Hispanic

22 (7\%)

Race

White

$250(86 \%)$

African American

$35(12 \%)$

Asian

$3(1 \%)$

Native American

4 (1\%)

Disease duration at Tecfidera start

Time since last relapse at

$4.4(0.003-34.94)$

Time since last re
Tecfidera start, $y$

$1.25(0.003-21.93)$

History of exposure to prior DMT

Teriflunomide (Aubagio)

$238(82 \%)$

Interferon $\beta-1 \alpha$ (Avonex)

$10(4 \%)$

Interferon $\boldsymbol{\beta}-1 \boldsymbol{\beta}$ (Betaseron)

32 (11\%)

$16(5 \%)$

Glatiramer acetate (Copaxone)

91 (31\%)

Fingolimod (Gilenya)

$10(4 \%)$

Interferon $\beta-1 \alpha$ (Rebif)

$26(9 \%)$

Natalizumab (Tysabri)

$48(16 \%)$

Other

$5(2 \%)$ 
A
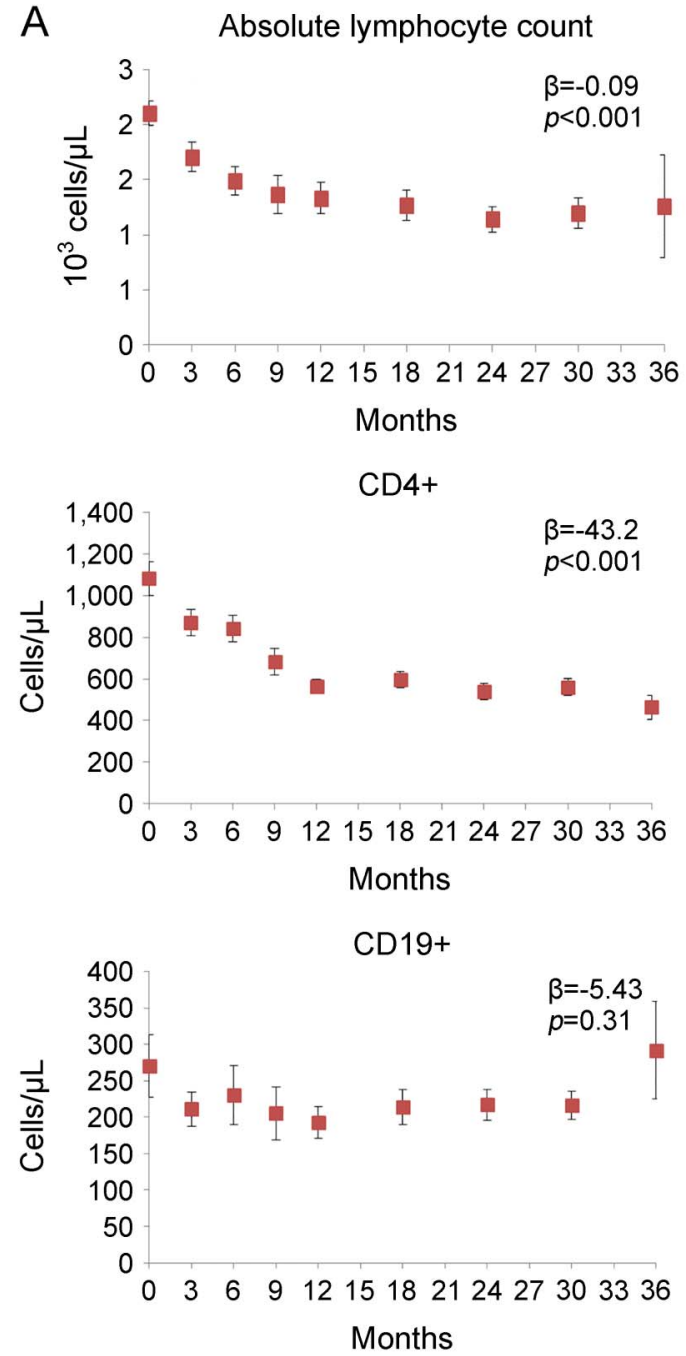

CD3+
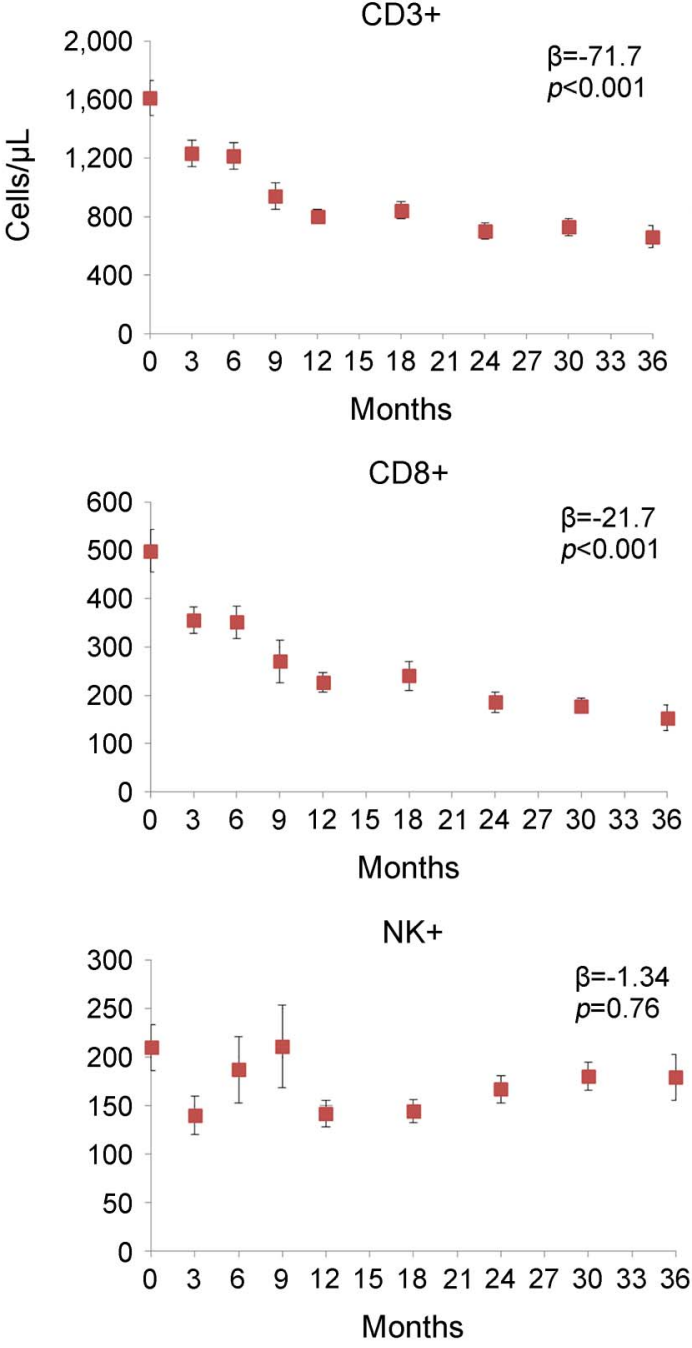

B

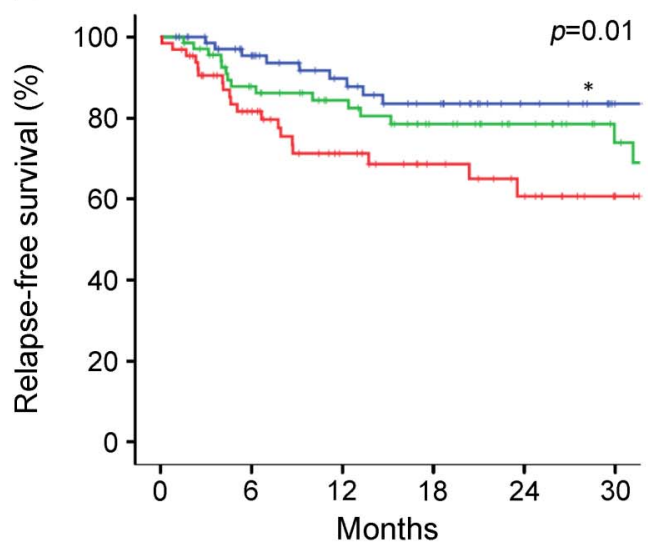

\begin{tabular}{|c|c|c|c|c|c|}
\hline \multirow{2}{*}{$\begin{array}{c}\text { ALC tertiles } \\
3 \text { or } 6 \\
\text { months }\end{array}$} & \multirow{2}{*}{$\begin{array}{c}\text { ALC } \\
\text { thresholds } \\
(\text { cells } / \mu \mathrm{L})\end{array}$} & \multirow{2}{*}{$\stackrel{\text { Total }}{\mathrm{N}}$} & \multirow{2}{*}{$\begin{array}{c}\text { Events } \\
\mathrm{N}\end{array}$} & \multicolumn{2}{|c|}{ Censored } \\
\hline & & & & $N$ & Percent \\
\hline 1 & $<1,200$ & 73 & 10 & 63 & 86.3 \\
\hline 2. & $1,210-1,800$ & 69 & 15 & 54 & 78.3 \\
\hline 3 & $>1,810$ & 65 & 20 & 45 & 69.2 \\
\hline Overall & & 207 & 45 & 162 & 78.3 \\
\hline
\end{tabular}

Significant reductions in white blood cell count and lymphocyte subsets were observed from baseline to 9 months (A; box plots display the mean and SD at each time point). Case processing summary demonstrating the time to first relapse according to absolute lymphocyte counts (ALCs) at months 3 and 6 after dimethyl fumarate initiation along with the number of clinical and radiologic events identified by ALC thresholds (B). The time to a first new clinical or radiologic event was extended when ALCs were reduced at 3 and 6 months, independent of baseline lymphocyte values and key baseline demographic and clinical data. NK $=$ natural killer.

$(r=0.44, p=0.004), \operatorname{CD} 8(r=0.50, p=0.001)$, $\mathrm{CD} 19(r=0.52, p=0.023)$, and NK $(r=0.47, p=$ $0.048)$ cells was identified. In addition, a relationship between NK cells and ALC $(r=0.66, p=0.003)$,
CD3 $(r=0.51, p=0.032)$, and CD4 $(r=0.53$, $p=0.026)$ was observed at 6 months.

Changes between baseline and 9 months were observed in WBC (monthly loss $[\beta]:-0.14, p<$ 
0.001), ALC $(\beta:-0.09, p<0.001), \operatorname{CD} 3(\beta$ : $-71.1, p<0.001), \mathrm{CD} 4(\beta:-43.2, p<0.001)$, and CD8 counts( $\beta$ : $-21.7, p<0.001)$. A longitudinal correlation between CD4 and CD19 subsets during the first 9 months of treatment was found $(p<0.001)$.

Time to first relapse was measured in accordance with ALCs at baseline $(\mathrm{n}=247), 3(\mathrm{n}=148)$, and 6 months $(\mathrm{n}=118)$. A greater risk of relapse was associated with higher ALCs at 3 months $(p=0.001$, hazard ratio [HR]: 1.82) and 6 months $(p=0.032$, HR: 1.73). When considering patients with lymphocyte counts at 6 months $(n=207)$, a decline in relapse-free survival was seen in patients with higher ALC values even after adjusting for age, sex, previous disease-modifying therapy (DMT) exposure, prior treatment type, and disease duration. Examination by tertile indicated a reduced risk in patients with lower ALC values $<1,200$ cells $/ \mu \mathrm{L}$ compared with midtier $(1,210-1,800$ cells $/ \mu \mathrm{L})$ and the highest tertile $(>1,810$ cells $/ \mu \mathrm{L})(p=0.01)$ (figure).

DISCUSSION Our findings revealed a meaningful reduction in total WBC counts, ALCs, and all lymphocyte subsets as soon as 3 months following DMF initiation; this pattern continued the first 9 months of treatment at which time counts began to plateau. The temporal profile of ALC changes also correlated with $\mathrm{T}$ - and B-cell subset data. Longitudinal correlations between CD4 and CD19 counts at baseline and month 9 of treatment were observed, suggesting that the clinical surveillance of patients may be effectively managed without lymphocyte subsets.

Our data suggest that laboratory assessments every 6 months are likely sufficient for the routine management of patients without lymphopenia, given the propensity for ALC values to stabilize after 9 months of treatment, which is in alignment with current package insert recommendations.

Beyond our observations to improve on the efficiency of the management of patients with MS treated with DMF, we identified an association between ALC values and clinical and radiologic markers of disease. Reductions in ALCs at months 3 and 6 after treatment were associated with improved clinical and radiologic outcomes independent of baseline lymphocyte counts, and ALCs $>1,800$ cells $/ \mu \mathrm{L}$ were more strongly associated with new disease behavior. This observation differs from previously published data that excluded new MRI activity in the definition of disease evolution and compared those with lymphopenia $(\geq 1$ ALC $<$ LLN) to those without (all ALCs $\geq$ LLN). ${ }^{9}$ The other study correlated outcomes with lymphopenia grades alone. ${ }^{10}$ Our findings may provide a more refined estimate of the association between ALC values and clinical response, understanding the potential compromise between safety and efficacy.

Our findings are limited by an assumption of full patient compliance with DMF, as objective measures of medication utilization beyond clinical inquiries during office visits were not used. Consequently, disease behavior measured by clinical and radiologic metrics could have been influenced by the degree of medication compliance. A modest number of clinical and radiologic events in total $(\mathrm{n}=45)$, the lack of systematically acquired neuroimaging studies and scheduled clinical assessments, and the use of multiple commercial laboratories to acquire data serve as potential limiting factors.

Finally, prospective studies are needed to confirm these findings. These data aid in refining surveillance recommendations and highlight the importance of diligent monitoring of ALCs especially within the first 9 months of treatment. ALCs alone may provide a better understanding of both the safety and therapeutic effect of DMF.

\section{AUTHOR CONTRIBUTIONS}

Ms. Wright: study concept and design, acquisition of data, analysis and interpretation of data, and drafting the manuscript and tables. Ms. Winkler: acquisition of data, analysis and interpretation of data, and drafting the manuscript. Mr. Newton: study concept and design, acquisition of data, analysis and interpretation of data, and drafting the manuscript and tables. Dr. Sormani: analysis and interpretation of data and drafting the manuscript, tables, and figure. Dr. Okuda: study concept and design, acquisition of data, analysis and interpretation, drafting the manuscript, and study supervision.

\section{STUDY FUNDING}

No targeted funding reported.

\section{DISCLOSURE}

K. Wright served on the scientific advisory board for Biogen, Genentech, and Genzyme and served on the speaker bureau for Acorda Therapeutics, Genentech, and Genzyme. M.D. Winkler served on the scientific advisory board for Genzyme; received travel funding from Genzyme and Genentech; and consulted for Genzyme and Genentech. B.D. Newton holds a patent for Methods for creating 3-dimensional representations exhibiting geometric and surface characteristics of brain lesions. M.P. Sormani served on the scientific advisory board for Medday, Merck Serono, Genzyme, Roche, Novartis, Teva, GeNeuro, and Biogen; received travel funding and/or speaker honoraria from Merck Serono, Teva, Genzyme, Novartis, Biogen, and Roche; consulted for Merck Serono, Biogen, Teva, Genzyme, Roche, Novartis, GeNeuro, and Medday; and received research support from Biogen, Teva, and Merck Serono. D.T. Okuda received travel funding and speaker honoraria from Acorda Therapeutics, Genentech, Genzyme, and Teva; consulted for Bayer, EMD Serono, Genzyme, Novartis, Acorda Therapeutics, Genzyme, and Teva Neuroscience; and received research support from Biogen. Go to Neurology.org/nn for full disclosure forms.

Received May 13, 2017. Accepted in final form August 1, 2017.

\section{REFERENCES}

1. Fox RJ, Miller DH, Phillips JT, et al; DEFINE Study Investigators. Placebo-controlled phase 3 study of oral BG-12 or glatiramer in multiple sclerosis. N Engl J Med 2012;367:1087-1097. 
2. Spencer CM, Crabtree-Hartman EC, Lehmann-Horn K, Cree BAC, Zamvil SS. Reduction of CD8(+) T lymphocytes in multiple sclerosis patients treated with dimethyl fumarate. Neurol Neuroimmunol Neuroinflamm 2015;2: e76; doi: 10.1212/NXI.0000000000000076.

3. Berkovich R, Weiner LP. Effects of dimethyl fumarate on lymphocyte subsets. Mult Scler Relat Disord 2015;4: 339-341.

4. Lehmann-Horn K, Penkert H, Grein P, et al. PML during dimethyl fumarate treatment of multiple sclerosis: how does lymphopenia matter? Neurology 2016;87: 440-441.

5. Nieuwkamp DJ, Murk JL, van Oosten BW, et al; PML in Dutch MS Patients Consortium. PML in a patient without severe lymphocytopenia receiving dimethyl fumarate. N Engl J Med 2015;372:1474-1476.
6. Package Insert T. Cambridge: Biogen Idec. Available at: https://www.tecfidera.com/pdfs/full-prescribinginformation.pdf. Accessed May 8, 2016.

7. Albrecht P, Bouchachia I, Goebels N, et al. Effects of dimethyl fumarate on neuroprotection and immunomodulation. J Neuroinflammation 2012;9:163.

8. Schulze-Topphoff U, Varrin-Doyer M, Pekarek K, et al. Dimethyl fumarate treatment induces adaptive and innate immune modulation independent of Nrf2. Proc Natl Acad Sci USA 2016;113:4777-4782.

9. Fox RJ, Chan A, Gold R, et al. Characterizing absolute lymphocyte count profiles in dimethyl fumarate-treated patients with MS: patient management considerations. Neurol Clin Pract 2016;6:220-229.

10. Longbrake EE, Cross AH. Dimethyl fumarate associated lymphopenia in clinical practice. Mult Scler 2015;21:796-797. 


\section{Neurology \\ Neuroimmunology \& Neuroinflammation}

\section{Patient outcomes influenced by reduced lymphocyte counts after dimethyl fumarate initiation}

Katy Wright, Mandy D. Winkler, Braeden D. Newton, et al.

Neurol Neuroimmunol Neuroinflamm 2017;4;

DOI 10.1212/NXI.0000000000000397

This information is current as of September 25, 2017

Updated Information \&

Services

References

Subspecialty Collections

Permissions \& Licensing

Reprints including high resolution figures, can be found at:

http://nn.neurology.org/content/4/6/e397.full.html

This article cites 9 articles, 2 of which you can access for free at: http://nn.neurology.org/content/4/6/e397.full.html\#\#ref-list-1

This article, along with others on similar topics, appears in the following collection(s):

MRI

http://nn.neurology.org//cgi/collection/mri

Multiple sclerosis

http://nn.neurology.org//cgi/collection/multiple_sclerosis

Information about reproducing this article in parts (figures,tables) or in its entirety can be found online at:

http://nn.neurology.org/misc/about.xhtml\#permissions

Information about ordering reprints can be found online: http://nn.neurology.org/misc/addir.xhtml\#reprintsus

Neurol Neuroimmunol Neuroinflamm is an official journal of the American Academy of Neurology.

Published since April 2014, it is an open-access, online-only, continuous publication journal. Copyright

Copyright (C) 2017 The Author(s). Published by Wolters Kluwer Health, Inc. on behalf of the American

Academy of Neurology.. All rights reserved. Online ISSN: 2332-7812.

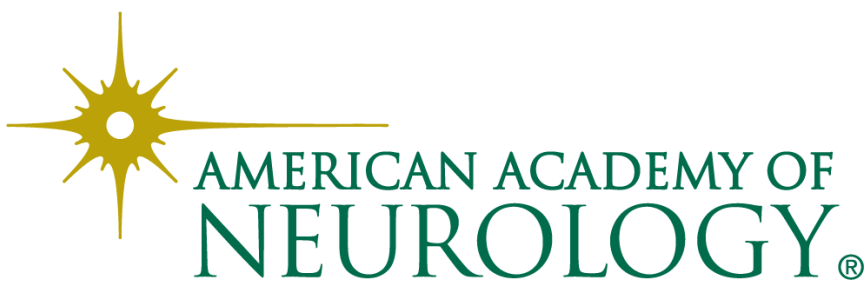

